\title{
Avaliação comparativa do padrão de normalidade do perfil facial em pacientes brasileiros leucodermas e em norte-americanos
}

\author{
Eduardo Sant'Ana*, Érika Uliam Kuriki**, William Arnett***,

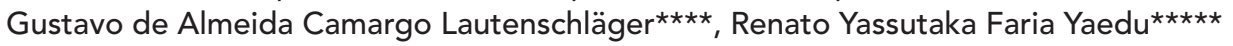

\section{Resumo}

Objetivo: ciente de que a cirurgia ortognática moderna se preocupa em planejar e diagnosticar os casos clínicos utilizando medidas obtidas de grandezas do perfil tegumentar dos pacientes - com o auxílio de imagens digitais empregadas em softwares de planejamento -, no presente estudo foi proposto aferir as medidas de brasileiros leucodermas de descendência européia e compará-las com as medidas já padronizadas por Arnett, com o intuito de criar novas medidas a serem seguidas por brasileiros que utilizam o software de predição cirúrgica Dolphin Imaging 9.0. Métodos: foram utilizadas radiografias cefalométricas de 31 pacientes com oclusão Classe I de Angle e harmonia facial. Todas as radiografias foram digitalizadas e inseridas no software Dolphin 9.0 e 16 pontos de tecido mole e 22 pontos do esqueleto facial foram marcados, seguindo-se exatamente as marcações da análise de Arnett e McLaughlin presentes no programa. Resultados: os resultados obtidos foram avaliados estatisticamente e mostram que o perfil do brasileiro é quase totalmente diferente do perfil norte-americano, exceção feita a apenas quatro pontos para os homens e outros quatro para as mulheres. Os brasileiros apresentam uma face menos protruída, um perfil mais convexo e menor proeminência do queixo do que o grupo controle. Conclusão: esses dados mostram a necessidade de se realizar algumas mudanças nas grandezas numéricas para que um perfeito diagnóstico e planejamento possam ser realizados em brasileiros, criando assim o padrão do perfil facial do brasileiro leucoderma de descendência européia.

Palavras-chave: Predição cirúrgica. Harmonia facial. Ortognática.

\footnotetext{
* Professor associado em Cirurgia e Traumatologia Bucomaxilofacial pela Faculdade de Odontologia de Bauru - USP

** Especialista em Implantodontia pelo HRAC-USP.

*** Especialista em Cirurgia e Traumatologia Bucomaxilofacial pela University of California/Los Angeles.

**** Mestre em Odontologia (área de concentração Estomatologia) pela Faculdade de Odontologia de Bauru - USP.

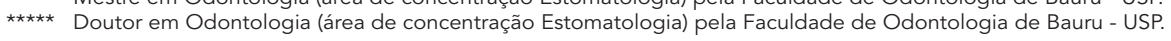




\section{INTRODUÇÃO}

A estética facial consagrou-se como um dos mais importantes objetivos da Ortodontia. A busca por uma face harmoniosa, além de uma oclusão estética e funcional ideais, norteia, contemporaneamente, de maneira marcante a conduta profissional.

Segundo Arnett e McLaughlin ${ }^{4}$, o conhecimento da beleza facial é uma característica nata aos olhos humanos. Entretanto, a definição objetiva dos componentes da beleza é extremamente difícil, pois essa objetividade é solapada pelas preferências pessoais, tendências culturais e pela crença de que a beleza se apresenta de formas diferentes e com características distintas. Para a maioria dos indivíduos, isso não é relevante sob o ponto de vista da objetividade. Porém, para os cirurgiões e ortodontistas, trata-se de um conceito da mais alta relevância. O estudo de Rivera et al. ${ }^{17}$ constatou que, dos pacientes que se dirigem ao consultório do cirurgião bucomaxilofacial, 71\% são movidos por razões estéticas, enquanto a melhora funcional e dos problemas articulares representam $47 \%$ e $28 \%$, respectivamente, monstrando a grande importância dada à estética facial.

Devido à grande valorização que a beleza vem tendo nos tempos atuais, a cobrança por uma melhor predição e por resultados cirúrgicos melhores forçou o desenvolvimento de novos instrumentos de diagnóstico - como a análise facial, que somou-se ao modelo de gesso e ao estudo cefalométrico. Hoje, é de reconhecimento que os efeitos nos tecidos moles, provenientes do tratamento dentofacial, oferecem os maiores benefícios funcionais e estéticos ${ }^{14}$. Mas, somente há pouco tempo, o modelo de pensamento do tecido mole, direcionando o tratamento dos problemas dentoesqueléticos, emergiu na Ortodontia e na Cirurgia Ortognática. Com isso, o resultado pós-operatório do perfil facial oferece uma notável precisão à predição, principalmente após a introdução de programas de computadores que aumentaram ainda mais a precisão do diagnóstico e do resultado cirúrgico.

\section{MATERIAL E MÉTODOS}

A amostra do presente estudo foi constituída por um grupo experimental e um grupo controle. Sendo que, para o grupo experimental, seguiramse os mesmos parâmetros do grupo controle.

De maneira simples e prática, pode-se dizer que os critérios de inclusão da amostra foram os seguintes:

1) pacientes leucodermas;

2) filhos de pais brasileiros, descendentes de mediterrâneos;

3) apresentando faces consideradas harmoniosas;

4) portadores de oclusão normal, sem mutilações nos arcos dentários;

5) nunca submetidos a tratamento ortodôntico;

6) idade entre 18 e 30 anos.

Oitenta e quatro indivíduos satisfizeram os critérios de inclusão acima descritos, sendo todos fotografados com a mesma máquina digital (Nikon Coolpix 990, Nikon, Tokyo/Japão), de forma padronizada, para a aquisição de fotografia em alta resolução (1280 x 960 pixels) de frente e de perfil.

De forma sistematizada, essas fotografias foram projetadas em condições controladas e avaliadas por 2 alunos de pós-graduação e um docente da área de Cirurgia. Dessa forma, 31 indivíduos foram escolhidos para integrar o grupo experimental.

A metodologia proposta teve a intenção de realizar a análise cefalométrica dos tecidos moles (ACTM) de todos os pacientes da amostra, seguindo os princípios descritos por Arnett et al. ${ }^{3}$, em 1999, e considerando os valores de sua análise como sendo o grupo controle do presente estudo.

No grupo controle, foi considerado o fato de que a análise cefalométrica dos tecidos moles (ACTM) foi proposta e descrita por Arnett et al. ${ }^{3}$ Mais uma vez, se torna importante salientar que os números encontrados pelos autores norteamericanos tornaram-se o grupo controle do presente estudo. 
Antes do início da análise cefalométrica, todos os pacientes do grupo experimental foram avaliados clinicamente em posição natural da cabeça, com os côndilos assentados e os lábios em repouso ${ }^{3}$.

Previamente às tomadas radiográficas, pequenos marcadores metálicos foram colocados no lado direito da face para marcar na radiografia as estruturas-chave do terço médio da face (Fig. 1). Essas estruturas essenciais da face média, embora perdidas nas radiografias convencionais, foram ressaltadas com a utilização desses marcadores, tornando-se um passo fundamental para o diagnóstico e tratamento das deficiências do terço médio da face. Também foi colocado um marcador na linha mento-pescoço (Fig. 1).

As radiografias foram realizadas utilizando-se sempre o aparelho de raios X do Departamento de Estomatologia da Faculdade de Odontologia de Bauru.

As telerradiografias foram digitalizadas com o Scanner Agfa Arcus II (Agfa, Morfsel, Bélgica), utilizando o programa Agfa Fotolook 3.5, no sistema RGB, com ampliação de $200 \%$ e resolução de $225 \mathrm{~d}$ pi. Todas as radiografias foram digitalizadas com o auxílio de uma régua própria do Dolphin (Dolphin 9.0, Dolphin Imaging \& Management

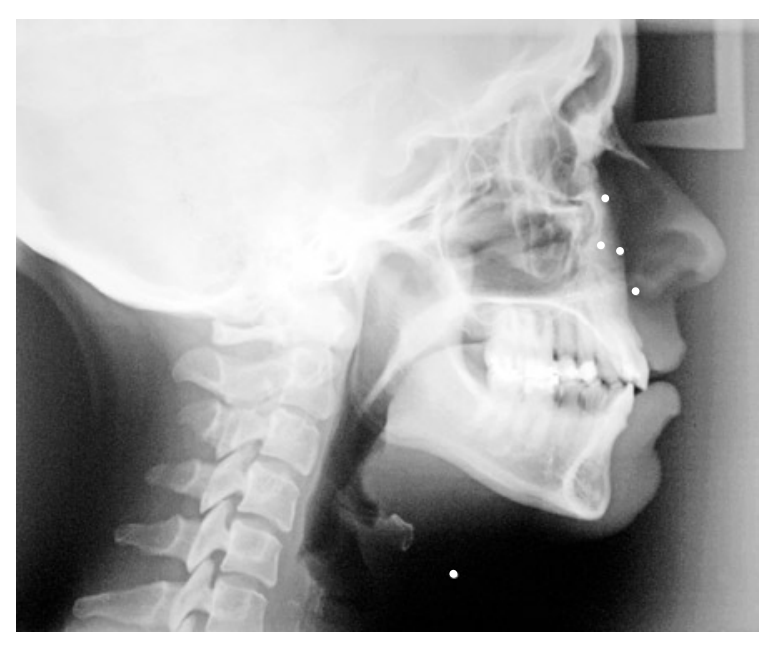

FIGURA 1 - Visualização dos marcadores metálicos na telerradiografia lateral.
Solutions, Califórnia/EUA), utilizada para se corrigir a magnificação da imagem radiográfica - causada durante a exposição dos filmes cefalométricos. Foram demarcados 16 pontos no perfil facial tegumentar e 22 pontos nas estruturas dentoesqueléticas, conforme visualizado na figura 2.

\section{RESULTADOS}

Os resultados obtidos com a análise cefalométrica dos tecidos moles e o erro do método podem ser visualizados nas tabelas apresentadas a seguir.

\section{DISCUSSÃO}

Quando a cirurgia ortognática surgiu, os autores preconizavam o diagnóstico e o plano de tratamento, para cada caso clínico, baseados exclusivamente nas más oclusões existentes e em grandezas cefalométricas $6,7,910,11,15,16,19$. Dentro dos poucos recursos da época, os modelos de gesso representavam um método de diagnóstico ortodôntico-cirúrgico importante, pois se acreditava que a correção da mordida baseada nesse meio de diagnóstico alcançaria os objetivos apropriados, inclusive a estética. Com o advento do cefalostato $^{6}$ e o desenvolvimento da cefalometria, as radiografias cefalométricas somaram-se aos modelos de gesso, passando a fazer parte do arsenal que os

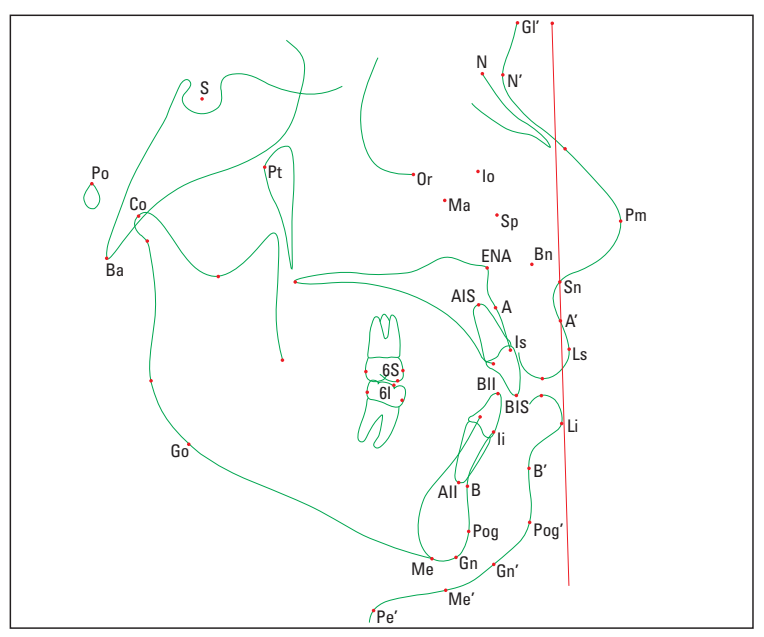

FIGURA 2 - Pontos de referência do traçado cefalométrico. 
Tabela 1 - Erro do método da análise cefalométrica do tecido mole utilizando o software Dolphin.

\begin{tabular}{|c|c|c|}
\hline & p (t Student) & erro Dahlberg \\
\hline IS-POM ( $\left.{ }^{\circ}\right)$ & 0,0492 & 6,21 \\
\hline II POMd $\left({ }^{\circ}\right)$ & 0,0046 & 3,55 \\
\hline overjet (mm) & 0,6148 & 0,16 \\
\hline overbite (mm) & 0,0320 & 0,41 \\
\hline altura posterior da maxila (POM-LVV) $\left({ }^{\circ}\right)$ & 0,1794 & 3,55 \\
\hline comprimento do lábio superior (mm) & 0,0354 & 1,26 \\
\hline gap interlabial (mm) & 0,0668 & 0,78 \\
\hline comprimento do lábio inferior (mm) & 0,8286 & 1,59 \\
\hline terço inferior da face $(\mathrm{mm})$ & 0,3838 & 1,18 \\
\hline comprimento facial (mm) & 0,1542 & 1,98 \\
\hline exposição de incisivo (mm) & 0,0112 & 0,46 \\
\hline comprimento anterior da maxila $(\mathrm{mm})$ & 0,5229 & 1,19 \\
\hline comprimento anterior da mandíbula $(\mathrm{mm})$ & 0,2839 & 1,03 \\
\hline espessura do lábio superior (mm) & 0,0089 & 2,00 \\
\hline espessura do lábio inferior (mm) & 0,4667 & 0,82 \\
\hline espessura do queixo (Pog-Pog') (mm) & 0,6208 & 0,39 \\
\hline espessura do mento (Me-Me') (mm) & 0,1026 & 1,15 \\
\hline glabela tegumentar (mm) & 0,0831 & 0,00 \\
\hline infra-orbital tegumentar (mm) & 0,5060 & 0,27 \\
\hline malar tegumentar (mm) & 0,9685 & 0,39 \\
\hline subpupilar tegumentar (mm) & 0,9839 & 0,38 \\
\hline pronasal (mm) & 0,5580 & 0,62 \\
\hline base nasal (mm) & 0,6232 & 0,57 \\
\hline subnasal (mm) & 0,000 & 0,00 \\
\hline ponto A tegumentar (mm) & 0,2162 & 0,89 \\
\hline lábio superior (mm) & 0,1330 & 1,42 \\
\hline borda do incisivo superior (mm) & 0,5276 & 1,74 \\
\hline ângulo labial $\left({ }^{\circ}\right)$ & 0,0500 & 20,06 \\
\hline ângulo nasolabial $\left({ }^{\circ}\right)$ & 0,7102 & 22,46 \\
\hline borda do incisivo inferior (mm) & 0,4537 & 1,95 \\
\hline lábio inferior (mm) & 0,4332 & 1,91 \\
\hline ponto $B$ tegumentar $(\mathrm{mm})$ & 0,8518 & 1,94 \\
\hline pogônio tegumentar (mm) & 0,6015 & 3,35 \\
\hline
\end{tabular}

profissionais tinham em mãos para diagnosticar e planejar o preparo ortodôntico-cirúrgico. Assim, um grande número de autores se engajou no estudo da cefalometria, possibilitando o surgimento de uma infinidade de análises, que se tornaram exaustivamente detalhadas ${ }^{8,15,18}$.

Por mais de uma década, as análises cefalomé- tricas, juntamente com os modelos de gesso, foram consideradas a única forma correta para o planejamento dos pacientes cirúrgicos e ortodônticos, pois indicavam o procedimento cirúrgico mais apropriado para o tratamento dos portadores de má oclusão esquelética que não poderiam ser submetidos exclusivamente ao tratamento ortodôntico. 
Tabela 2 - Comparação das medidas dentoesqueléticas da análise cefalométrica do tecido mole de brasileiros com o padrão americano para o gênero feminino.

\begin{tabular}{|c|c|c|c|c|}
\hline \multirow{2}{*}{ medidas dentoesqueléticas } & \multicolumn{2}{|c|}{ brasileiros } & \multicolumn{2}{|c|}{ americanos } \\
\hline & média & d.p. & média & d.p. \\
\hline Mx altura posterior (MxOP-TVL) $\left({ }^{\circ}\right)$ & 97,65 & 3,97 & 95,60 & 1,80 \\
\hline Mx1 a Mx plano oclusal $\left({ }^{\circ}\right)$ & 56,34 & 5,62 & 56,80 & 2,50 \\
\hline Md1 a Md plano oclusal ( $\left(^{\circ}\right)$ & 62,04 & 5,43 & 64,30 & 3,20 \\
\hline overjet (mm) & 3,34 & 1,02 & 3,20 & 0,40 \\
\hline overbite (mm) & 1,94 & 1,47 & 3,20 & 0,70 \\
\hline
\end{tabular}

Tabela 3 - Comparação das medidas dentoesqueléticas da análise cefalométrica do tecido mole de brasileiros com o padrão americano para o gênero masculino.

\begin{tabular}{|c|c|c|c|c|}
\hline \multirow{2}{*}{ medidas dentoesqueléticas } & \multicolumn{2}{|c|}{ brasileiros } & \multicolumn{2}{|c|}{ americanos } \\
\hline & média & d.p. & média & d.p. \\
\hline Mx altura posterior (MxOP-TVL) $\left({ }^{\circ}\right)$ & 99,13 & 5,27 & 95,00 & 1,40 \\
\hline Mx1 a Mx plano oclusal $\left({ }^{\circ}\right)$ & 54,14 & 7,02 & 57,80 & 3,00 \\
\hline Md1 a Md plano oclusal $\left(^{\circ}\right)$ & 63,66 & 6,20 & 64,00 & 4,00 \\
\hline overjet (mm) & 3,19 & 0,84 & 3,20 & 0,60 \\
\hline overbite (mm) & 2,48 & 2,31 & 3,20 & 0,70 \\
\hline
\end{tabular}

Tabela 4 - Comparação das medidas dos tecidos moles da análise cefalométrica do tecido mole de brasileiros com o padrão americano para o gênero feminino.

\begin{tabular}{|c|c|c|c|c|}
\hline \multirow{2}{*}{ medidas dos tecidos moles } & \multicolumn{2}{|c|}{ brasileiros } & \multicolumn{2}{|c|}{ americanos } \\
\hline & média & d.p. & média & d.p. \\
\hline espessura do lábio superior (mm) & 12,34 & 1,66 & 12,60 & 1,80 \\
\hline espessura do lábio inferior (mm) & 9,36 & 1,62 & 13,60 & 1,40 \\
\hline espessura do queixo (Pog-Pog') (mm) & 12,37 & 2,08 & 11,80 & 1,50 \\
\hline espessura do mento (Me-Me') (mm) & 9,54 & 1,55 & 7,40 & 1,60 \\
\hline ângulo nasolabial ( $\left.{ }^{\circ}\right)$ & 110,79 & 7,99 & 103,50 & 6,80 \\
\hline ângulo do lábio superior $\left({ }^{\circ}\right)$ & 4,74 & 8,96 & 12,10 & 5,10 \\
\hline
\end{tabular}

Tabela 5 - Comparação das medidas dos tecidos moles da análise cefalométrica do tecido mole de brasileiros com o padrão americano para o gênero masculino.

\begin{tabular}{|c|c|c|c|c|}
\hline \multirow{2}{*}{ medidas dos tecidos moles } & \multicolumn{2}{|c|}{ brasileiros } & \multicolumn{2}{|c|}{ americanos } \\
\hline & média & d.p. & média & d.p. \\
\hline espessura do lábio superior (mm) & 15,06 & 2,19 & 14,80 & 1,40 \\
\hline espessura do lábio inferior (mm) & 9,59 & 2,20 & 15,10 & 1,20 \\
\hline espessura do queixo (Pog-Pog') (mm) & 14,48 & 2,30 & 13,10 & 2,30 \\
\hline espessura do mento (Me-Me') (mm) & 9,58 & 2,62 & 8,80 & 1,30 \\
\hline ângulo nasolabial $\left({ }^{\circ}\right)$ & 107,36 & 8,54 & 106,40 & 7,70 \\
\hline ângulo do lábio superior $\left({ }^{\circ}\right)$ & 4,26 & 8,04 & 8,30 & 5,40 \\
\hline
\end{tabular}


Tabela 6 - Comparação das medidas do comprimento facial da análise cefalométrica do tecido mole de brasileiros com o padrão americano para o gênero feminino.

\begin{tabular}{|c|c|c|c|c|}
\hline \multirow{2}{*}{ medidas do comprimento facial } & \multicolumn{2}{|c|}{ brasileiros } & \multicolumn{2}{|c|}{ americanos } \\
\hline & média & d.p. & média & d.p. \\
\hline altura facial $(\mathrm{mm})$ & 128,10 & 5,83 & 124,60 & 4,70 \\
\hline comprimento do lábio superior (mm) & 21,09 & 2,17 & 21,00 & 1,90 \\
\hline espaço interlabial (mm) & 3,51 & 1,29 & 3,30 & 1,30 \\
\hline comprimento do lábio inferior (mm) & 48,14 & 3,69 & 46,90 & 2,30 \\
\hline terço inferior da face (mm) & 72,74 & 4,55 & 71,10 & 3,50 \\
\hline overbite (mm) & $-8,48$ & 0,04 & 3,20 & 0,70 \\
\hline exposição de incisivo $\mathrm{Mx1}$ (mm) & 4,28 & 1,54 & 4,70 & 1,60 \\
\hline altura anterior $\mathrm{Mx}(\mathrm{mm})$ & 25,36 & 2,59 & 25,70 & 2,10 \\
\hline altura anterior $\mathrm{Md}(\mathrm{mm})$ & 49,31 & 2,34 & 48,60 & 2,40 \\
\hline
\end{tabular}

Tabela 7 - Comparação das medidas do comprimento facial da análise cefalométrica do tecido mole de brasileiros com o padrão americano para o gênero masculino.

\begin{tabular}{|c|c|c|c|c|}
\hline \multirow{2}{*}{ medidas do comprimento facial } & \multicolumn{2}{|c|}{ brasileiros } & \multicolumn{2}{|c|}{ americanos } \\
\hline & média & d.p. & média & d.p. \\
\hline altura facial (mm) & 131,90 & 5,51 & 137,70 & 6,50 \\
\hline comprimento do lábio superior (mm) & 23,51 & 2,20 & 24,40 & 2,50 \\
\hline espaço interlabial (mm) & 2,54 & 1,37 & 2,40 & 1,10 \\
\hline comprimento do lábio inferior (mm) & 49,68 & 3,47 & 54,30 & 2,40 \\
\hline terço inferior da face (mm) & 75,72 & 4,77 & 81,10 & 4,70 \\
\hline overbite (mm) & $-8,47$ & 0,06 & 3,20 & 0,70 \\
\hline exposição de incisivo Mx1 (mm) & 2,79 & 2,13 & 3,90 & 1,20 \\
\hline altura anterior $\mathrm{Mx}(\mathrm{mm})$ & 26,30 & 2,71 & 28,40 & 3,20 \\
\hline altura anterior $\mathrm{Md}(\mathrm{mm})$ & 51,90 & 2,80 & 56,00 & 3,00 \\
\hline
\end{tabular}

Bell ${ }^{5}$ relata em seu livro que, apesar de uma parte significante dos pacientes obter resultados faciais favoráveis, muitos foram prejudicados esteticamente. Isso pode ser explicado pelo fato de que, naquela época, pouca atenção era dispensada ao perfil tegumentar, resultando em imprecisões, principalmente sob o ponto de vista estético e também nas dificuldades técnicas da cirurgia, que era muito limitada na época.

Hoje, com o avanço das técnicas cirúrgicas e da Medicina, pode-se dizer que a realidade é outra. O progresso das técnicas cirúrgicas nos permite a chance de realmente movimentar os ossos da maxila e da mandíbula em todos os planos do espaço, com total precisão e predição, por meio de planejamentos digitais ultra-especializados e seguros.

Atualmente, os planejamentos são realizados de maneira que o primeiro passo ao se examinar um paciente cirúrgico, segundo as orientações de Arnett e Bergman ${ }^{1}$, é saber o que devemos enxergar no seu rosto para poder corrigir, na totalidade, os defeitos estéticos por ele apresentados e, além disso, proporcionar a esse indivíduo as chaves de 
Tabela 8 - Comparação das medidas - da análise cefalométrica do tecido mole - da projeção à LVV dos brasileiros com o padrão americano para o gênero feminino.

\begin{tabular}{|c|c|c|c|c|}
\hline \multirow{2}{*}{ medidas das projeções à LVV } & \multicolumn{2}{|c|}{ brasileiros } & \multicolumn{2}{|c|}{ americanos } \\
\hline & média & d.p. & média & d.p. \\
\hline tecido mole da glabela (mm) & $-8,48$ & 0,04 & $-8,50$ & 2,40 \\
\hline tecido mole da rima orbitária $(\mathrm{mm})$ & $-19,98$ & 1,35 & $-18,70$ & 2,00 \\
\hline tecido mole da bochecha (mm) & $-21,74$ & 2,31 & $-20,60$ & 2,40 \\
\hline tecido mole da subpupil (mm) & $-15,12$ & 1,76 & $-14,80$ & 2,10 \\
\hline tecido mole da base do nariz (mm) & $-11,33$ & 1,56 & $-12,90$ & 1,10 \\
\hline projeção nasal (mm) & 16,31 & 1,88 & 16,00 & 1,40 \\
\hline subnasal (mm) & 0,00 & 0,00 & 0,00 & 0,00 \\
\hline tecido mole do ponto $\mathrm{A}^{\prime}(\mathrm{mm})$ & $-0,23$ & 1,42 & $-0,10$ & 1,00 \\
\hline ponto anterior do lábio superior (mm) & 3,17 & 2,44 & 3,70 & 1,20 \\
\hline $\mathrm{Mx1}(\mathrm{mm})$ & $-9,96$ & 3,89 & $-9,20$ & 2,20 \\
\hline $\operatorname{Md} 1(\mathrm{~mm})$ & $-13,31$ & 4,10 & $-12,40$ & 2,20 \\
\hline ponto anterior do lábio inferior (mm) & 0,88 & 4,15 & 1,90 & 1,40 \\
\hline tecido mole do ponto $B^{\prime}$ (mm) & $-8,00$ & 4,65 & $-5,30$ & 1,50 \\
\hline tecido mole do pogônio (mm) & $-5,69$ & 5,70 & $-2,60$ & 1,90 \\
\hline
\end{tabular}

Tabela 9 - Comparação das medidas - da análise cefalométrica do tecido mole - da projeção à LVV dos brasileiros com o padrão americano para o gênero masculino.

\begin{tabular}{|c|c|c|c|c|}
\hline \multirow{2}{*}{ medidas das projeções à LVV } & \multicolumn{2}{|c|}{ brasileiros } & \multicolumn{2}{|c|}{ americanos } \\
\hline & média & d.p. & média & d.p. \\
\hline tecido mole da glabela $(\mathrm{mm})$ & $-8,47$ & 0,06 & $-8,00$ & 2,50 \\
\hline tecido mole da rima orbitária $(\mathrm{mm})$ & $-23,51$ & 3,34 & $-22,40$ & 2,70 \\
\hline tecido mole da bochecha (mm) & $-26,09$ & 4,07 & $-25,20$ & 4,00 \\
\hline tecido mole da subpupil (mm) & $-18,21$ & 3,81 & $-18,40$ & 1,90 \\
\hline tecido mole da base do nariz (mm) & $-12,90$ & 2,79 & $-15,00$ & 1,70 \\
\hline projeção nasal (mm) & 17,01 & 1,93 & $-17,40$ & 1,70 \\
\hline subnasal (mm) & 0,00 & 0,00 & 0,00 & 0,00 \\
\hline tecido mole do ponto $A^{\prime}(\mathrm{mm})$ & $-0,76$ & 1,47 & $-3,00$ & 1,00 \\
\hline ponto anterior do lábio superior $(\mathrm{mm})$ & 3,01 & 2,02 & 3,30 & 1,70 \\
\hline Mx1 (mm) & $-12,98$ & 3,26 & $-12,10$ & 1,80 \\
\hline $\operatorname{Md} 1(\mathrm{~mm})$ & $-16,15$ & 3,31 & $-15,40$ & 1,90 \\
\hline ponto anterior do lábio inferior (mm) & 0,48 & 3,36 & 1,00 & 2,20 \\
\hline tecido mole do ponto $B^{\prime}(\mathrm{mm})$ & $-10,15$ & 4,23 & $-7,10$ & 1,60 \\
\hline tecido mole do pogônio (mm) & $-5,71$ & 4,96 & $-3,50$ & 1,80 \\
\hline
\end{tabular}

oclusão propostas por Andrews. Com isso, por um lado, os procedimentos cirúrgicos tornaramse muito maiores e mais complexos, por outro, os resultados tornaram-se absurdamente melhores do que os obtidos anteriormente. Ainda, há uma maior indicação cirúrgica para o tratamento das discrepâncias dentoesqueléticas por parte dos ortodontistas, que vivenciam e participam de uma fase muito boa da Cirurgia Ortognática. O tratamento ortodôntico-cirúrgico, que era considerado pelos ortodontistas a última opção para tentar solucionar um caso já submetido a todos os recursos ortodônticos, tornou-se a melhor opção para intervir nas más oclusões esqueléticas. 
Apesar da consagração das técnicas de análise facial no diagnóstico e planejamento dos casos ortodôntico-cirúrgicos, vários autores ainda contestam sua importância e persistem na utilização de análises cefalométricas esqueléticas para o tratamento de pacientes adultos cirúrgicos. Essas análises esqueléticas são incapazes de expressar a realidade do perfil tegumentar e preservam a cirurgia ortognática como uma ciência capaz de resolver simplesmente a má oclusão dentária, ou seja, um procedimento cirúrgico meramente funcional.

Em 1993, Arnett e Bergman ${ }^{1,2}$ publicaram um trabalho, dividido em dois artigos, que abordava a análise facial de uma forma bastante apurada, mostrando uma perspectiva um pouco diferente de como se deveria avaliar uma face, com o intuito de obter o resultado totalmente esperado pelos pacientes e profissionais. Nesses artigos, os autores consideram a cirurgia ortognática uma ciência fundamentalmente estética e funcional, tentando demonstrar, com palavras claras, que a estética é primordial para o sucesso dos pacientes cirúrgicos.

Cientes das dificuldades apresentadas pelos profissionais em questão e preocupados em padronizar uma forma precisa da análise facial, visando criar um protocolo real de planejamento e tratamento cirúrgico para os pacientes com deformidades esqueléticas, Arnett et al. ${ }^{3}$, em 1999, realizaram um estudo num grupo de pessoas que apresentavam perfil normal e oclusão perfeita, sem nunca terem se submetido a tratamento ortodôntico ou cirúrgico. Desse estudo resultou um novo tipo de análise cefalométrica dos tecidos moles, baseado em uma linha vertical verdadeira que corre à frente do rosto do paciente e toca o ponto subnasal. Com isso, os autores conseguiram quantificar numericamente as grandezas de todo o perfil facial dos pacientes, medindo todos os pontos selecionados em relação à linha vertical verdadeira. As medidas do perfil dos pacientes com discrepâncias dentoesqueléticas podem ser comparadas ao perfil numérico considerado "ideal", demonstrando a importância dessas grandezas numéricas e sua aplicação no diagnóstico e planejamento dos casos ortodôntico-cirúrgicos. Tornou-se possivel determinar a quantidade de movimentação cirúrgica, em milímetros, necessária para atingir o padrão correto estabelecido pelos autores.

Neste último século, o desenvolvimento tecnológico permitiu muitos avanços na área da informática. Com o auxílio de um software de planejamento cefalométrico (Dolphin Imaging 9.0), o mesmo utilizado por Arnett e com grandezas numéricas por ele padronizadas ${ }^{3}$, tornou-se muito mais simples planejar uma cirurgia ortognática e diagnosticar todos os defeitos dentoesqueléticos e de perfil facial utilizando como valores-padrão os números de leucodermas norte-americanos. Atualmente esse software é uma realidade para o mundo todo, porém as mesmas imprecisões de resultados obtidas com diferentes tipos de análises podem ocorrer, pois os números representativos das grandezas dos tecidos moles não condizem com seres humanos do mundo todo.

A partir dos resultados obtidos no presente estudo, pode-se observar que as grandezas numéricas encontradas no contorno do perfil mole de brasileiros, utilizando-se exatamente a mesma linha vertical verdadeira utilizada por Arnett, apresentam-se significantemente diferentes para a maioria dos pontos que mapeiam o perfil tegumentar da amostra brasileira. Em média dos números computados, o grupo brasileiro apresenta um perfil mais convexo, com menor protrusão do osso malar, menor exposição dos incisivos superiores e mento menos protruído; o sulco mentolabial mostra-se menos pronunciado e um formato menos protruído dos tecidos moles do queixo. Também, a altura facial inferior encontra-se diminuída, quando comparada ao perfil norte-americano. Em outras palavras, pode-se dizer que, de uma maneira geral, o rosto do brasileiro leucoderma é totalmente diferente do norte-americano leucoderma, assumindo grandezas mais significantes no terço inferior da face, com a altura facial diminuída e o terço inferior menos protruído, determinando um formato médio 


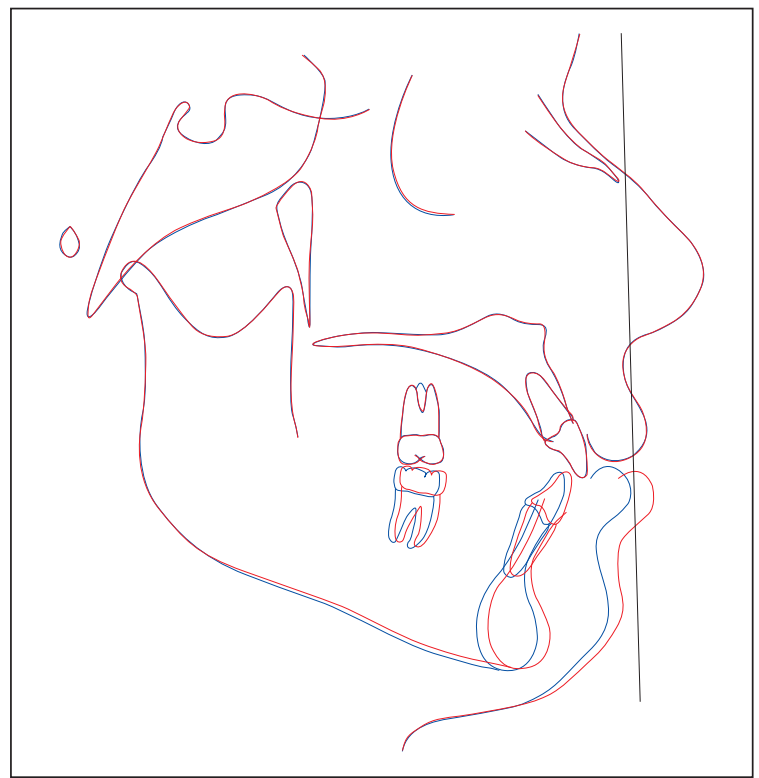

FIGURA 3 - Comparação do padrão brasileiro da análise cefalométrica do tecido mole com o padrão americano. Em vermelho observa-se o perfil do padrão americano, em azul o perfil do tecido mole do padrão brasileiro e em preto a linha vertical verdadeira.

marcantemente mais convexo (Fig. 3). Os valores obtidos mostram que os brasileiros possuem um perfil menos marcante e mais discreto, quando comparado aos norte-americanos apresentados no grupo controle de Arnett et al. ${ }^{3}$

Com total certeza, muitos estudos ainda devem ser realizados no Brasil, pois não se pode ignorar o fato de que vivemos em um país de muitas raças distintas e os números encontrados no presente estudo referem-se, apenas e somente, a um grupo seleto de indivíduos leucodermas de descendência européia que vive no estado de São Paulo. Não há dúvidas de que os números encontrados nesse estudo devem apresentar-se um pouco diferentes quando a análise for aplicada no sul do país, ou no norte e nordeste, bem como em brasileiros negros, mulatos, descendentes de japoneses, índios, etc.

Acreditamos, ainda, que a análise cefalométrica dos tecidos moles utilizando a linha vertical verdadeira é uma forma muito precisa de avaliar, diagnosticar e planejar o tratamento dos pacientes adultos que irão ser submetidos à intervenção ortodôntico-cirúrgica para correção das deformidades faciais. Porém, até mesmo para aqueles que estão muito habituados a utilizá-la, existem situações específicas em que o bom senso e o senso estético devem ser considerados, com o intuito de obter os melhores resultados cirúrgicos possíveis. Não podemos deixar de considerar ainda que a análise das chaves de harmonia facial deve sempre ser considerada quando se ambiciona a precisão nos resultados. Também, não se pode deixar de considerar que, para alcançar os melhores resultados, a habilidade técnica para manipular o software de predição e a habilidade para realizar as técnicas cirúrgicas mais precisas devem estar em perfeito sincronismo, exigindo muitas vezes, do cirurgião apurado, treinamento técnico tanto do software quanto das técnicas cirúrgicas mais precisas e atuais, que podem conduzir aos resultados mais perfeitos possíveis.

\section{CONCLUSÃO}

A partir da comparação das grandezas numéricas obtidas de pacientes brasileiros com os números estabelecidos para pacientes leucodermas norte-americanos, dentro das condições determinadas neste estudo experimental, pode-se concluir que:

- Os números obtidos na análise do perfil mole dos brasileiros são diferentes dos encontrados nos norte-americanos, exceto em quatro pontos para o gênero masculino e outros quatro para o gênero feminino.

- Os brasileiros possuem a altura facial um pouco menor, quando comparados aos norte-americanos.

- Os brasileiros apresentam o terço inferior da face menos protruído, quando comparados aos norte-americanos.

Pelos números obtidos no presente estudo, pode-se padronizar, para indivíduos brasileiros, a utilização da análise cefalométrica dos tecidos moles através do software Dolphin.

Enviado em: fevereiro de 2008 Revisado e aceito: maio de 2008 


\title{
Comparative evaluation of the facial profile normality standards in Brazilian Caucasian patients and in North American patients
}

\begin{abstract}
Aim: Considering that modern orthognathic surgery is mainly concerned in planning and diagnosing clinical cases by the use of patients' soft tissue measurements obtained from digital images used in planning software, the aim of this study is to establish Caucasian Brazilians measures and to compare them to the standard North American measures. Methods: For this, a total of 31 Angle's Class I patients not previously submitted to orthodontic treatment and presenting harmonious facial features were invited to participate in the study as volunteers. The patients were initially photographed in frontal and lateral views and, afterwards, cephalograms were obtained. The images were digitized, adjusted and indexed in Dolphin's image software. In order to precede cephalometric analysis, a total of 16 soft tissue profile points and 22 hard tissue profile points were demarcated, accordingly to American original measurements used in Dolphin's digital image program. After, all cephalograms were again evaluated to determine intra-examiner error according to paired Student's t test. Mean and standard error measures were obtained and compared to American measures by unpaired Student's $t$ test with $95 \%$ of confidence level. Results: The results obtained have shown that all measurements, except for 4 points in male and 4 points in female, are significantly different between Brazilian and American samples. Data show that Brazilians' soft tissue profile is almost completely different from American's, with a less protrusive face, shorter chin projection and a more convex profile. Conclusion: This suggests the necessity of performing some changes in numerical values to obtain an ideal diagnosis and planning of orthognathic surgery in Brazilians.
\end{abstract}

Key words: Soft tissue cephalometric. Orthognatic surgery.

\section{REFERÊNCIAS}

1. ARNETT, G. W.; BERGMAN, R. Facial keys to orthodontic diagnosis and treatment planning. Part I. Am. J. Orthod. Dentofacial Orthop., St. Louis, v. 103, no. 5, p. 299-312, May 1993.

2. ARNETT, G. W.; BERGMAN, R. Facial keys to orthodontic diagnosis and treatment planning. Part II. Am. J. Orthod. Dentofacial Orthop., St. Louis, v. 103, no. 5, p. 395-411, May 1993.

3. ARNETT, G. W.; JELIC, J.; KIM, J.; CUMMINGS, D.; BERESS, A.; WORLEY, JR., C.; CHUNG, B.; BERGMAN, R. Soft tissue cephalometric analysis: diagnosis and treatment planning of dentofacial deformity. Am. J. Orthod. Dentofacial Orthop. St. Louis, v. 116, no. 3, p. 239-253, Sept. 1999.

4. ARNETT, G. W.; McLAUGHLIN, R. Facial and dental planning for orthodontists and oral surgeons. Edinburgh: C. V. Mosby, 2004

5. BELL, W. Modern practice in orthognathic and reconstrutive surgery. Philadelphia: W. B. Saunders, 1992.

6. BROADBENT, B. A new $x$-ray technique and its application to orthodontia. Angle Orthod., Appleton, v. 1, p. 45-66, 1931.

7. BRODIE, A. On the growth pattern of the human head: from the third month to the eight years of life. Am. J. Anat., New York, v. 68, p. 209-262, 1941.

8. BURSTONE, C. Lip posture and its significance in treatment planning. Am. J. Orthod., St. Louis, v. 53, p. 262-284, 1967.

9. DOWNS, W. Variations in facial relationships: their significance in treatment and prognosis. Am. J. Orthod., St. Louis, v. 34, p. 812-840, 1948

10. KROGMAN, W.; SASSOUNI, V. (Ed.). A syllabus in roentgenographic cephalometry. Philadelphia: College Offset, 1957.

11. MARGOLIS, H. The axial inclination of the mandibular incisors. Am. J. Orthod. Oral Surg., St. Louis, v. 29, p. 571-594, 1943.

12. MOSS, J.; LINNEY, A.; LOWEY, M. The use of threedimensional techniques in facial esthetics. Semin. Orthod., Philadelphia, v. 1, no. 2, p. 94-104, June 1995.
13. PARK, Y.; BURSTONE, C. Soft-tissue profile: fallacies of hard-tissue standards in treatment planning. Am. J. Orthod. Dentofacial Orthop., St. Louis, v. 90, p. 52-62, 1986

14. PROFFIT, W.; WHITE JR., R.; SARVER, D. Contemporary treatment of dentofacial deformity. St. Louis: C. V. Mosby, 2003.

15. RICKETTS, R. Cephalometric synthesis: an exercise in stating objectives planning treatment with tracings of the head roentgenogram. Am. J. Orthod., St. Louis, v. 46, p. $647-673,1960$.

16. RIEDEL, R. An analysis of dentofacial relationships. Am. J. Orthod., St. Louis, v. 43, p. 103-119, 1957

17. RIVERA, S.; HATCH, J.; DOLCE, C.; BAYS, R.; VAN SICKEL, S. J.; RUGH, J. Patients' own reasons and patient-perceived recommendations for orthognathic surgery. Am. J. Orthod. Dentofacial Orthop., St. Louis, v. 118, no. 2, p. 134-141, Aug. 2000.

18. STEINER, C. Cephalometrics as a clinical tool. In: KRAUS, B.; RIEDEL, R. Vistas in Orthodontics. Philadelphia: Lea \& Febiger, 1962. p. 131-161.

19. WYLIE, W. The assessment of anteroposterior dysplasia. Angle Orthod., Appleton, v. 17, p. 97-109, 1947
Endereço para correspondência Eduardo Sant'ana

Al. Octávio Pinheiro Brisola, 9-75

CEP: 17.012-901 - Bauru / SP

E-mail: esantana@usp.br 